\title{
Influence of Hydroxypropyl Cellulose on Molecular Relaxations of Epoxy-amine Networks
}

\author{
Maria Inez G. Miranda, Dimitrios Samios, Liane de L. Freitas, Clara I. D. Bica \\ Instituto de Química, UFRGS
}

\begin{abstract}
A dynamic mechanical analysis (DMTA) study was conducted on epoxy-amine networks crosslinked in the presence of low contents of hydroxypropyl cellulose (HPC). The epoxy resin chosen was diglycidylether of bisphenol-A (DGEBA) and the crosslinker was 4,4'-diaminodiphenylmethane (DDM). In the glassy region, primary $(\alpha)$ and secondary $(\beta, \gamma)$ relaxations originating from the epoxy and HPC components were well detected. Two primary relaxations of neat epoxy and epoxy/HPC systems, referred to as $\alpha_{\text {epoxy }}$ and $\alpha_{\text {epoxy }}$, could be detected, showing a particular glassy behavior for the systems studied in comparison with systems cured in bulk. The main relaxation temperature $\mathrm{T}_{\alpha}$ (at the peak of $\alpha_{\text {epoxy }}$ relaxation) of the epoxy systems increased slightly with the addition of HPC. The activation energy for this transition $\left(\mathrm{T}_{\alpha}\right)$ of the epoxy-amine networks was determined both from $\tan \delta$ and the peak temperatures for the loss modulus measured at various frequencies. The activation energy of the $\alpha_{\text {epoxy }}$ relaxation determined from the loss modulus was more reliable than that based on $\tan \delta$. The addition of HPC lowered the activation energy of this $\alpha_{\text {epoxy }}$ relaxation.
\end{abstract}

Keywords: Epoxy, relaxations, hydroxypropylcellulose, activation energy.

\section{Introduction}

In recent years there has been an increasing interest in the development of new applications of materials obtained from renewable sources. It was showed for example that thermosets can be obtained by curing epoxy resins produced by the epoxidation of vegetable oils ${ }^{[1,2]}$. Another example is cellulosic materials, since cellulose is the most abundant organic polymer in the planet and recently has been used in nano and microcellulose fibers-filled epoxy systems ${ }^{[3]}$. In a previous publication ${ }^{[4]}$, we studied the role of hydroxypropyl cellulose (HPC), a cellulose ether, inside an epoxy matrix during the formation process of the epoxy network by differential scanning calorimetry (DSC). On the beginning of the reaction we concluded that HPC in the epoxy matrix acts as an accelerator-catalyst resulting in an acceleration factor of about $30 \%$. Beyond the minimum temperature $\mathrm{T}_{\min }-$ which is defined as the temperature corresponding to the minimum point showed by the exothermic peaks during the curing reaction of an epoxy system measured by DSC - the behaviors of the rate constant $(\mathrm{k})$ and the frequency factor $(\mathrm{A})$ indicate that the crosslinking process becomes slower with HPC acting as an inhibitor of the reaction.

The aim of this study is to investigate the dynamic mechanical properties of epoxy-amine systems crosslinked in the presence of hydroxypropyl cellulose (HPC) in order to achieve information about the evolution of relaxations already existing and detect new characteristic transitions. The transitions originating from the epoxy matrix and HPC as well as the possible modifications caused in these transitions by the presence of the other compound in the mixture can be detected by DSC and DMTA. Bearing in mind that DSC was previously employed in the investigation of the curing kinetics of this epoxy-amine/HPC system ${ }^{[4]}$, the remarkable sensitivity of DMTA towards primary and secondary molecular relaxations will be highlighted here. The relaxations were investigated in systems with HPC contents from 0 to $10 \mathrm{wt}$. (\%) since phase separation took place at higher HPC contents as observed in our earlier DSC experiments.

Considering that DMTA curves are affected by the frequency of the applied deformation, the shift in the position of the maxima of the peaks can be related to the activation energy of the relaxation ${ }^{[5]}$. These curves can be analyzed using an Arrhenius-type expression, taking the temperature T at which the tan $\delta$ or E" reach their maxima over a range of frequencies. The Arrhenius plot can thus yield the activation energy (Ea) for what is termed the relaxation process. In the last years the Arrhenius equation has been applied to various polymer systems aiming the determination of the activation energy of some relaxations, as for example the glass transition, due to the application of Arrhenius equation in the prediction of long-term material performance ${ }^{[6-14]}$. It was also reported that monitoring the activation energy of the glass transition can be useful for detecting changes due to material aging ${ }^{[10]}$.

In this work it was studied in glassy region the primary $(\alpha)$ and secondary $(\beta, \gamma)$ relaxations originating from both the epoxy and HPC components and their mutual interactions.

\section{Experimental}

The diglycidylether of bisphenol-A, DGEBA (CY-205, Ciba-Geigy) was cured with a stoichiometric amount of a tetrafunctional aromatic diamine, 4,4'-diaminodiphenylmethane, DDM (HT-972, Ciba-Geigy). The epoxy monomer is a viscous resin with an epoxide equivalent weight (EEW) of 182-196 g/eq. and n' $=0.14$ (data furnished by manufacturer), where n' represents the degree of polymerization. The amine curing agent is a crystalline solid (melting point of $90{ }^{\circ} \mathrm{C}$ ) with an amine equivalent weight of 99g/eq. A molar ratio 2:1 (DGEBA/DDM) was used which corresponds to the stoichiometric formulation. Hydroxypropyl cellulose (HPC) was manufactured by Aldrich with a nominal molecular weight of 100,000 g.mol ${ }^{-1}$. In Figures 1a-c the molecular structures of DGEBA, DDM and an idealized structure of HPC are presented. The molar substitution value (MS) of the HPC sample used in this study was determined by $\mathrm{H}^{1}$-NMR as described by $\mathrm{Ho}^{[17]}$ and it was found to be 4.5 (MS represents the average number of hydroxypropyl groups $\left(\mathrm{CH}_{2} \mathrm{CH}\left(\mathrm{CH}_{3}\right) \mathrm{O}\right)$ per anhydroglucose unit). The samples were prepared by casting of DGEBA/DDM and HPC solutions in order to obtain suitable films for the DMTA measurements. Amounts of DGEBA/DDM (molar ratio 2:1) were dissolved in chloroform at a concentration of 250 g.L. $\mathrm{L}^{-1}$. HPC was also dissolved in chloroform at a concentration of 25 g. $\mathrm{L}^{-1}$. Both solutions were mixed in different proportions in order to 
obtain systems whose composition varied from 0 to $10 \mathrm{wt}$. (\%) and pure HPC and epoxy control samples were analyzed. The mixture was maintained under constant stirring during four hours at room temperature. The solutions were put into aluminum plates in order to evaporate the excess of solvent and stayed at room temperature during seven days. The samples were then submitted to reduced pressure for ten hours and finally they were oven-cured for 1 hour at $120{ }^{\circ} \mathrm{C}$ to guarantee that complete cure took place as reported in our previous papers ${ }^{[4,15,16]}$. In order to verify that the samples were fully cured, DSC scans were made for cured samples originated from casting preparation and the thermograms are showed in Figure 2. The analysis was made using DSC technique (DSC-4 Perkin-Elmer equipment, samples weighting $10 \mathrm{mg}$, under inert atmosphere and at $\left.5{ }^{\circ} \mathrm{C} \cdot \mathrm{min}^{-1}\right)$ to the samples obtained under casting in the $0 \mathrm{wt}$. (\%) HPC, 8 wt. (\%) HPC and 100 wt. (\%) HPC concentrations. From the thermograms showed in Figure 2 it is possible to see (at 0 wt. (\%) HPC) that there was a single transition around $135{ }^{\circ} \mathrm{C}$ related to main glass transition event (Tg). At $100 \mathrm{wt}$. (\%) HPC, it is possible to assign around $200{ }^{\circ} \mathrm{C}$ the liquid-crystalline transition of HPC. It can be seen also (in the 0 wt. (\%) HPC, 8 wt. (\%) HPC samples) that there is not any residual heat which confirms that the samples were fully cured. IR analysis (cured samples in $\mathrm{KBr}$ ) did not detect the presence of solvent. The cured samples did not show turbidity at concentrations smaller than $10 \mathrm{wt} \%$ HPC but above $10 \mathrm{wt}$ (\%) they were opaque. Afterwards the cured samples were cut in a rectangular shape with $2 \times 0.5 \mathrm{~cm}$ and had around $0.6 \mathrm{~mm}$ thickness. The dynamic mechanical experiments were performed in a Mk-II PL-DMTA Polymer Laboratories using the combined head in tensile mode. The temperature was scanned at $2{ }^{\circ} \mathrm{C} \cdot \mathrm{min}^{-1}$ from -150 to $200{ }^{\circ} \mathrm{C}$. The DMTA measurements were carried out at different frequencies $(0.3,1,3$ and $10 \mathrm{~Hz})$.

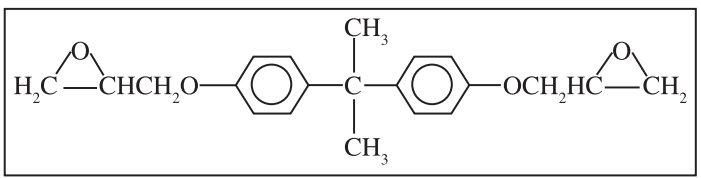

(a)

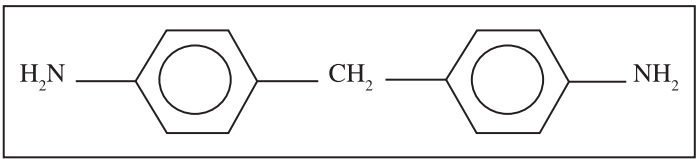

(b)

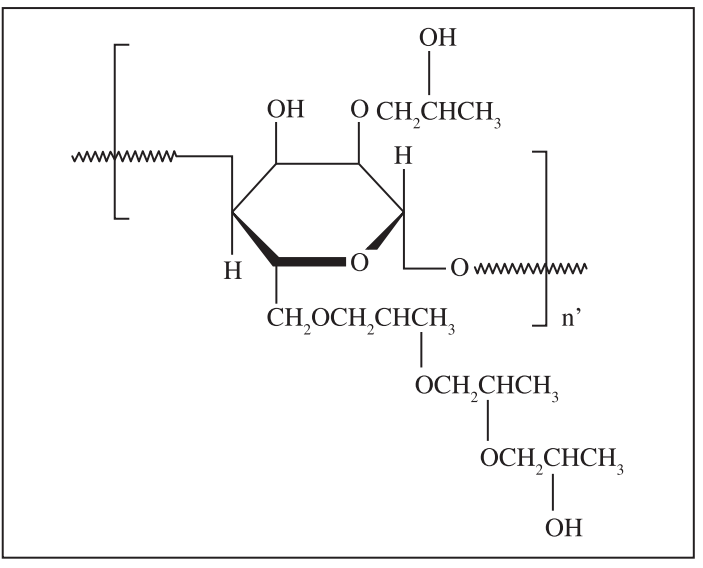

(c)

Figure 1. a) Molecular structure of DGEBA, b) Molecular structure of DDM, c) Molecular structure of HPC.

\section{Results and Discussion}

The dynamic mechanical properties of epoxy systems containing different amounts of HPC are shown in Figures 3a, b. Figure 3a shows a schematic representation of the temperature dependence of $\log \mathrm{E} "$ at $10 \mathrm{~Hz}$ for the pure epoxy system, the HPC and a mixture

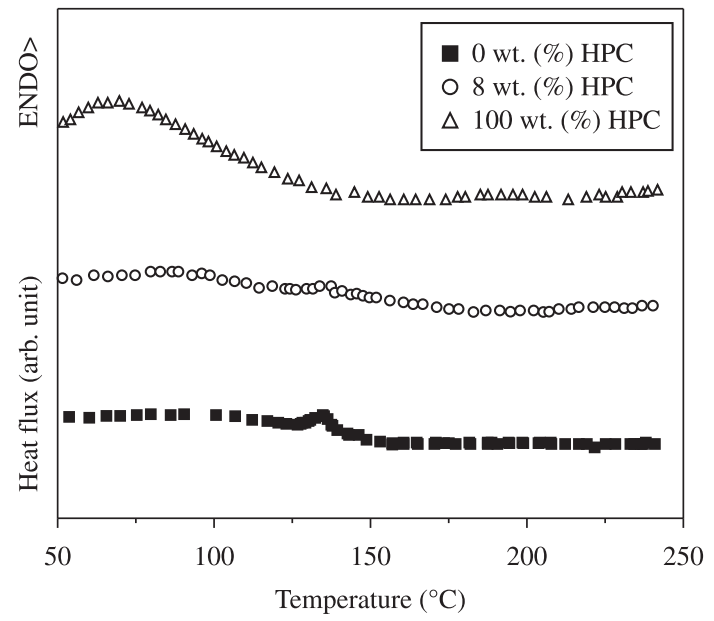

Figure 2. Schematic representation of heat flux (arb. unit) versus temperature curves for the pure epoxy system, the pure HPC and a mixture containing 8 wt. (\%) of $\mathrm{HPC}$ at $5{ }^{\circ} \mathrm{C} \cdot \mathrm{min}^{-1}$.

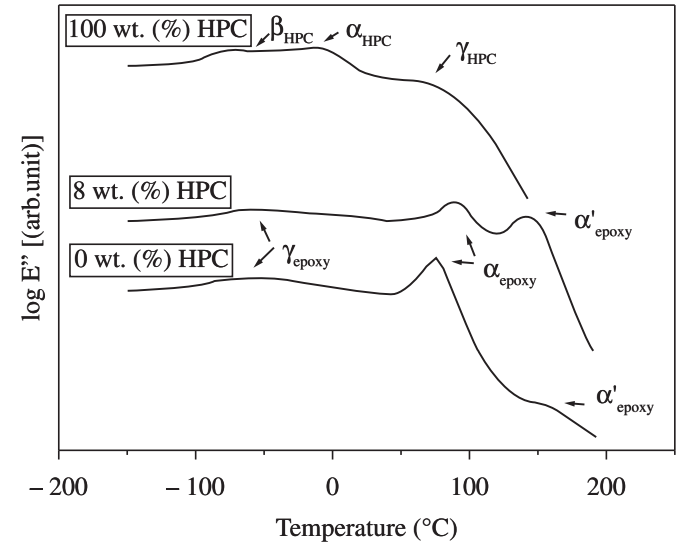

(a)
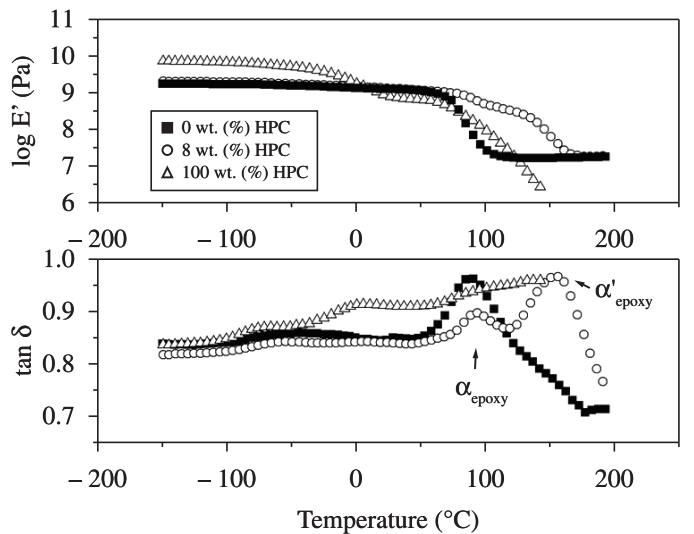

(b)

Figure 3. a) Schematic representation of $\log \mathrm{E}$ " versus temperature curves for the pure epoxy system, the pure HPC and a mixture containing $8 \mathrm{wt}$. (\%) of $\mathrm{HPC}$ at $10 \mathrm{~Hz}, \mathrm{~b})$ Temperature dependence of $\log \mathrm{E}$ ' and $\tan \delta$ for the pure epoxy system, HPC and a mixture containing 8 wt. (\%) of HPC at $10 \mathrm{~Hz}$. 
containing 8 wt. (\%) of HPC. From the three relaxations reported for the DGEBA/DDM epoxy system ${ }^{[18]}$, the following ones were observed in this study: the $\alpha$ relaxations (so-called $\alpha_{\text {epoxy }}$ and $\alpha^{\prime}{ }_{\text {epoxy }}$ ) which are in the typical glassy to rubber-like transition region and a secondary relaxation $(\gamma)$, called here $\gamma_{\text {epoxy }}$. The latter one corresponds to the broad transition at temperatures around $-60{ }^{\circ} \mathrm{C}$ and it is reported to be due to the movement of the portion glycidyl-amine related to the portion of copolymerized DGEBA with $\mathrm{DDM}^{[19,20]}$. The $\beta$ relaxation was not observed in our systems since there is no signal around $30{ }^{\circ} \mathrm{C}$; in the literature ${ }^{[18]}$ it is attributed to partially reacted segments and/or to the heterogeneities of sample. In the $\log$ E" curve for the pure HPC three relaxations can be observed. The $\alpha_{\text {HPC }}$ relaxation is attributed to the glass transition region of $\mathrm{HPC}$, the $\beta_{\mathrm{HPC}}$ relaxation to side groups and main chain movements of HPC while the $\gamma_{\text {HPC }}$ relaxation is due to the presence of a supramolecular order related to the formation of a liquid crystalline

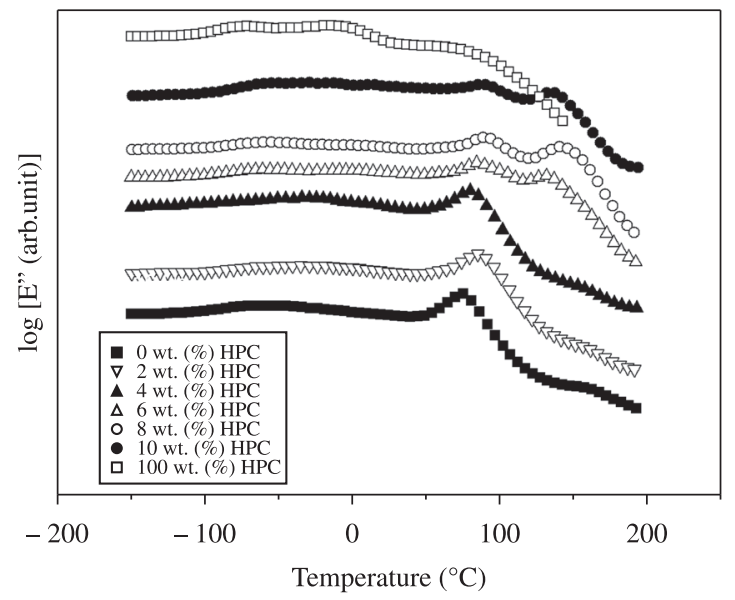

Figure 4. Log E" versus temperature curves for the pure systems and mixtures with different amounts of HPC at $10 \mathrm{~Hz}$.

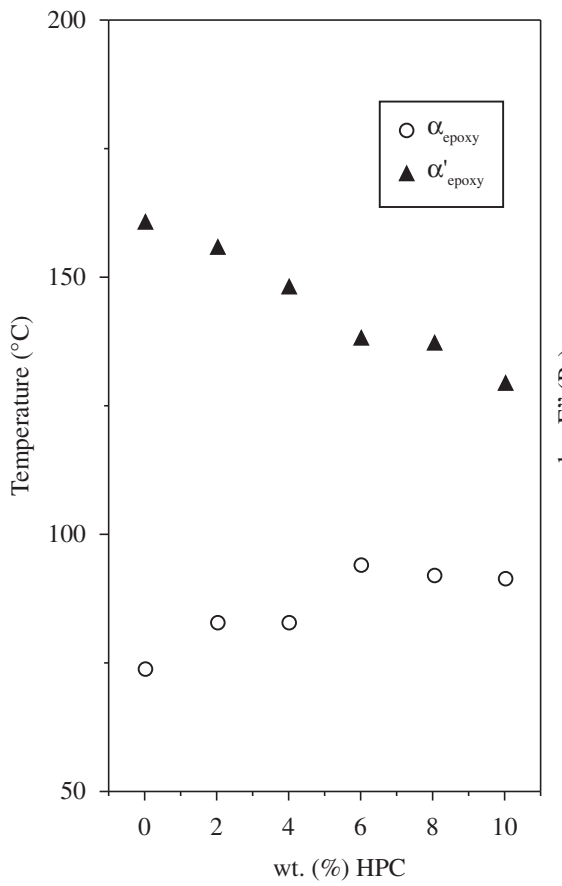

(a) phase induced by the solvent during the casting process, as assigned by Glasser ${ }^{[21]}$. The $\alpha$ relaxations of the pure materials are appointed on this Figure 3 a to 0 wt. $(\%)$ of HPC $\left(\alpha_{\text {epoxy }}\right)$ and 100 wt. $(\%)$ of $\operatorname{HPC}\left(\alpha_{\mathrm{HPC}}\right)$. Figure $3 \mathrm{~b}$ shows the temperature dependence of $\log \mathrm{E}^{\prime}$ and $\tan \delta$ at $10 \mathrm{~Hz}$ for the pure epoxy system, the HPC and a mixture containing 8 wt. (\%) of HPC.

It is well known that HPC is not a flexible polymer but a semi-rigid one. As cellulose ether, its main chain is the rigid one of cellulose. The lateral propyl groups give some flexibility to HPC but not to the extent of a totally flexible polymer. In fact, under casting and in temperatures below $0{ }^{\circ} \mathrm{C}$ showed in Figure $3 \mathrm{~b}(\log \mathrm{E}$ ' versus Temperature), the pure HPC presents higher log E' values than epoxy systems. Besides that, the addition of $8 \mathrm{wt}$. (\%) HPC on epoxy matrix does not affect significantly the log E' comparing to the pure epoxy matrix. This behavior was observed only below $\alpha_{\text {epoxy }}$

In the $\log$ E" (Figure 3a) and $\tan \delta$ (Figure 3b) curves for the epoxy system containing 8 wt. (\%) of HPC a relaxation around $150{ }^{\circ} \mathrm{C}$ and called the $\alpha^{\prime}$ epoxy relaxation can be observed. At the same temperature range the $\alpha_{\text {epoxy }}^{\text {epoxy }}$ relaxation also appears as a small peak in the curve for the pure epoxy system. It is clear in Figure 3a, that there are two glass transitions of the pure system, $\alpha_{\text {epoxy }}$ detected around $150{ }^{\circ} \mathrm{C}$ and $\alpha_{\text {epoxy }}$ around $80^{\circ} \mathrm{C}$.

Considering that DMTA experiments were run at a lower heating rate than DSC experiments, it is acceptable that the transition $\alpha_{\text {epoxy }}$ detected around $80{ }^{\circ} \mathrm{C}\left(2{ }^{\circ} \mathrm{C} \cdot \mathrm{min}^{-1}\right)$ corresponds to the transition around $135^{\circ} \mathrm{C}$ detected by DSC $\left(5^{\circ} \mathrm{C} \cdot \mathrm{min}^{-1}\right)$. Besides that, in Figure 4 it was observed that $\alpha_{\text {epoxy }}$ (at 0 wt. (\%) HPC and 8 wt. (\%) HPC) occurs at the same temperature, as suggested by the DSC experiment shown in Figure 2. This assumption corroborates the statement that $\alpha_{\text {epoxy }}$ transition is the main primary transition and in addition it can be taken to evaluate kinetic data. Moreover in Figure $5 \mathrm{a}, \alpha_{\text {epoxy }}$ did not change with increasing HPC content whereas $\alpha_{\text {epoxy }}^{\prime}$ did. This is an additional evidence that $\alpha_{\text {epoxy }}$ is the true main epoxy matrix primary transition.

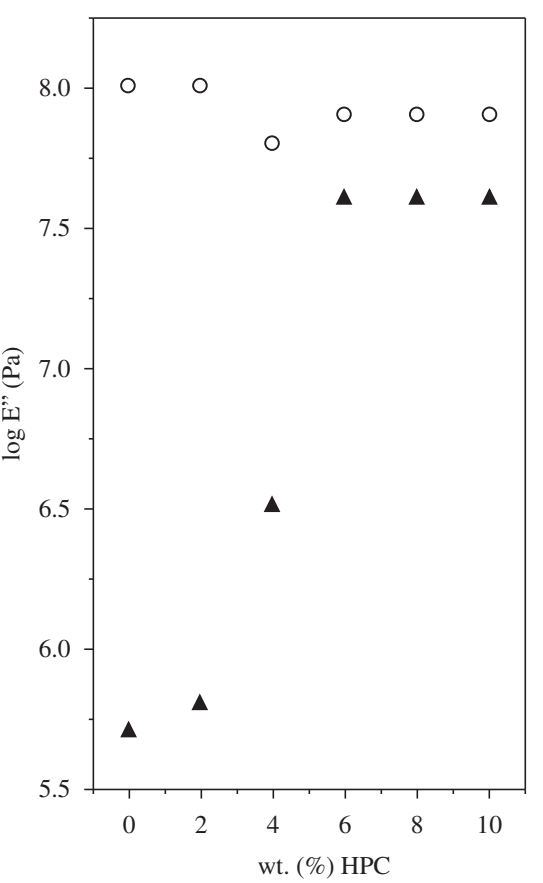

(b)

Figure 5. a) Temperature maxima values for different relaxations as a function of HPC content for the measurements carried out at $10 \mathrm{~Hz}$, b) Log E" maxima values for different relaxations as a function of HPC content for the measurements carried out at $10 \mathrm{~Hz}$. 
Epoxy systems cured under casting could present different glassy regions from that of the bulk systems. This was evident in those epoxy systems where the appearance of two glass transitions is the remarkable difference between systems obtained by casting and by bulk. The main transition $\alpha_{\text {epoxy }}$ was chosen to be analyzed in this paper because it can be more quantitatively and accurately evaluated, considering further parameters such as peak temperatures of relaxation for use in kinetic methods.

Figure 4 shows the curves of $\log$ E" versus temperature for the pure systems and mixtures with different amounts of HPC which were shifted along the y-axis to show the appearance of $\alpha_{\text {epoxy }}^{\prime}$ and $\alpha_{\text {epoxy }}$ relaxations. It was evidenced in this figure that $\alpha_{\text {epoxy }}^{\text {epoxy }}$ relaxation intensity got nearby $\alpha_{\text {epoxy }}$ relaxation intensity with the increasing of HPC content ( 6 to $10 \mathrm{wt}$. (\%)). The influence of HPC on the $\alpha_{\text {epoxy }}$ relaxation can be figured out by the fact that the $\alpha_{\text {epoxy }}$ relaxation turns to be more clearly defined in presence of HPC. The $\gamma_{\mathrm{HPC}}$ relaxation influences on epoxy matrix producing a region with characteristics of a glassy region ( $\alpha_{\text {epoxy }}^{\prime}$ relaxation) assigned at higher peak temperatures than those determined to $\alpha_{\text {epoxy }}$ relaxation. Under casting procedure this $\alpha_{\text {epoxy }}^{\prime}$ relaxation could indicate the presence of a second microphase within the epoxy matrix and the increase of HPC content could emphasize the existence of this microphase.

Figure 5 shows log E" peak temperature $\left(\mathrm{T}_{\text {peak }}\right)$ and its corresponding value at $\mathrm{T}_{\text {peak }}$ of the different relaxations as a function of the HPC content for the measurements carried out at $10 \mathrm{~Hz}$. In Figure 5a it can be observed a slight increase on temperature maxima values of $\alpha_{\text {epoxy }}$ (so-called $\mathrm{T}_{\alpha}$ ) relaxations with the increasing HPC concentration in the epoxy matrix. This was also observed in the DSC measurements ${ }^{[4]}$ and shows that the molecular mobility and chain flexibility of the epoxy matrix decrease. The $\alpha$ ' relaxation suffers a remarkable decrease. The values of $\log \mathrm{epoxy}$ " maxima (Figure $5 b$ ) remain practically constant for the $\alpha_{\text {epoxy }}$, while they show an important increase for the $\alpha^{\prime}$ epoxy relaxation (from $\log \mathrm{E}^{\prime \prime}=5.75$ to $\log \mathrm{E} "=7.50$ ) when the HPC content increases until 6 wt. (\%). At higher concentrations the $\log \mathrm{E}$ " values remain constant. The same behavior was observed at the frequencies of $0.3,1$ and $3 \mathrm{~Hz}$. The increase of $\log$ E" (Figure 5b) and the decrease of log E" peak temperature $\left(\mathrm{T}_{\text {peak }}\right)$ (Figure 5a) of $\alpha_{\text {epoxy }}$ relaxation could indicate that in this region HPC acts as a plasticizing. In HPC-epoxy systems the presence of $\alpha_{\text {epoxy }}$ and $\alpha^{\prime}$ epoxy relaxations distinguishes the glassy region from that typical of those systems cured in bulk where a single glass transition was reported ${ }^{[4]}$. It is known that the $\mathrm{T}_{\mathrm{g}}$ values observed for epoxy systems obtained from casting could be usually 30 degrees $\left({ }^{\circ} \mathrm{C}\right)$ lower than those observed for systems obtained in bulk $^{[18]}$. This difference can be explained taking into account the influence of solvent during the curing process. The presence of solvent decreases the chemical reaction probability of DDM with DGEBA and increases the probability of association between DGEBA molecules ${ }^{[18]}$ leading to lower crosslinking densities. Also the association of DGEBA molecules with solvent molecules may lead to the same effect during casting. Taking this into account, the effect of residual quantities of solvent during the curing process could be also contributing to the appearance of a second relaxation on the epoxy glass transition range. Figure 6 shows the loss modulus ( $\log$ E") at the frequencies of 0.3 (Figure 6a) and $1 \mathrm{~Hz}$ (Figure 6b) as a function of temperature. The relaxations (E" maxima) are shifted to higher temperatures with increasing frequency. Considering the small peak which appears at high temperatures we have no sufficient evidences to confirm the presence of a liquid crystalline transition of HPC by DMTA measurements, as assigned by DSC ${ }^{[4]}$.

The behavior of the storage modulus (E') was also examined. For HPC contents higher than 6 wt. (\%), it was verified that the E' modulus presents two slightly detectable changes in the slope of the curve on the glass transition region (data not shown) indicating the presence of a second relaxation $\alpha^{\prime}$ epoxy on higher temperature in glassy state characteristic of regions with different extent of chain mobility, due to the constraints arising from the higher interaction of epoxy matrix and HPC. At temperatures below the region where $\alpha_{\text {epoxy }}^{\prime}$ and $\alpha_{\text {epoxy }}$ relaxations are present, the curves of the loss modulus (E") show peaks that can be attributed to secondary molecular relaxations. In fact, in glassy region showed in Figures $6 a$ and $b$, the addition of HPC (6 to $10 \mathrm{wt}$. (\%)) affects slightly the log E" of epoxy matrix. It is not possible to infer about mechanical properties as stiffness of the samples considering this tendency on loss modulus and storage modulus behaviors. These well-defined maxima take place at the same temperature regions where the storage modulus (E') curves show slightly detectable changes in the slope of the curve. The peaks of main $\mathrm{T}_{\alpha}$ on $\mathrm{E}$ " and $\tan \delta$ curves will therefore be used to the kinetic analysis.

The determination of the activation energy for the $\alpha_{\text {epoxy }}$ relaxation at $\mathrm{T}_{\alpha}$, as the main temperature on glassy state, obtained by dynamic mechanical analysis was carried out, considering the temperature shift of the E" and $\tan \delta$ maxima when different frequencies were used in the measurements.

Considering epoxy systems, there are only a few studies in the literature concerning the use of DMTA for determining the activation energies based on the shift of the $\tan \delta$ or E" peaks of $\mathrm{T}_{\mathrm{g}}{ }^{[7,9]}$ with frequency. Here we use both to calculate the activation

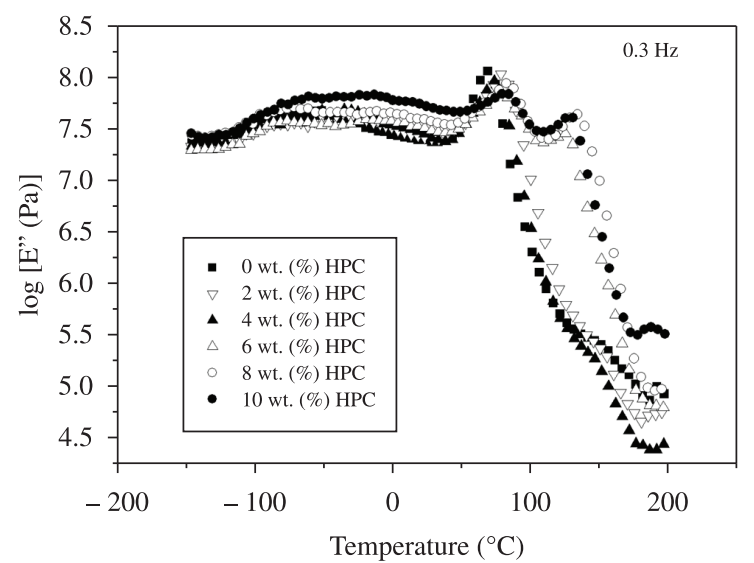

(a)

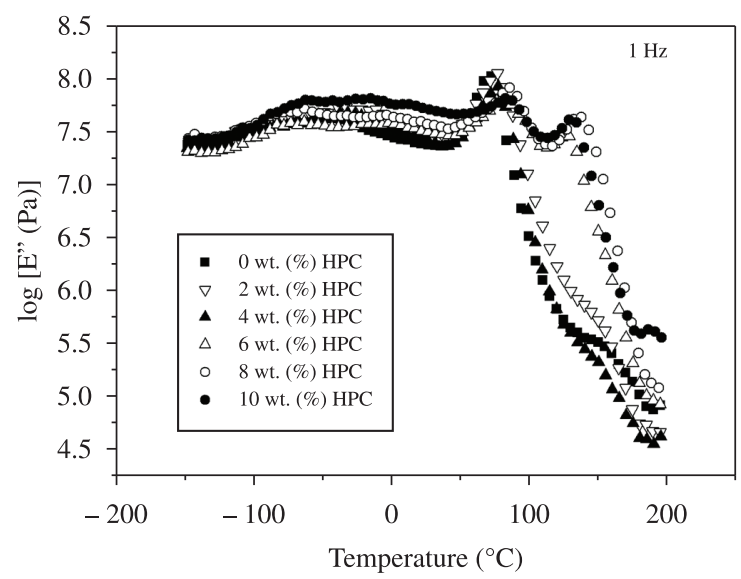

(b)

Figure 6. a) Logaritmus of the loss modulus as a function of temperature for different HPC contents at frequencies of $0.3 \mathrm{~Hz}, \mathrm{~b}$ ) Logaritmus of the loss modulus as a function of temperature for different HPC contents at frequencies of $1 \mathrm{~Hz}$. 
energies (Ea) and compare the results as well as the reliability of the results according to the correlation coefficients $\left(\mathrm{R}^{2}\right)$. It is known that a relaxation will be seen as a peak on the loss modulus (E") versus temperature curves when the frequency of the segmental movement coincides with the experimentally applied frequency. At higher frequencies the process of dissipation will occur at higher temperatures where the molecular motion is faster. This shift on the position of the maxima, with the frequency is related to the activation energy of each transition. In reactional processes the rate constant $\mathrm{k}(\mathrm{T})$ can be usually described by the Arrhenius equation,

$$
\mathrm{k}(\mathrm{T})=\mathrm{Ao} \exp (-\mathrm{Ea} / \mathrm{RT})
$$

By analogy, this equation can be written as a function of frequency as

$$
\ln (\mathrm{f})=\ln \mathrm{Ao}-\mathrm{Ea} / \mathrm{RT}
$$

where $\mathrm{f}$ is the frequency in $\mathrm{Hz}, \mathrm{Ea}$ the activation energy of the transition in energy/mol and $\mathrm{T}$ is the maximum absolute transition temperature $\left(\mathrm{T}_{\alpha}\right.$ at $\left.\alpha_{\text {epoxy }}\right)$. The slope of the straight line in the plot $\ln (\mathrm{f})$ versus $1 / \mathrm{T}$ is $\mathrm{Ea} / \mathrm{R}$. The DMTA experiments were carried out at $2{ }^{\circ} \mathrm{C} \cdot \mathrm{min}^{-1}$ because according to kinetic studies ${ }^{[4,7,22]}$ at higher heating rates thermal and material diffusion become dominant factors and higher activation energies were calculated. So the Arrhenius relationship is valid only when the maximum heating rate in DMTA tests does not exceed $2{ }^{\circ} \mathrm{C} \cdot \mathrm{min}^{-1}$ and consistent activation energy values can be obtained ${ }^{[7]}$. Table 1 presents the results of activation energies at different concentrations of HPC, calculated from $\tan \delta$ and $\mathrm{E}^{\prime}$ peaks of the $\alpha_{\text {epoxy }}$ relaxation $\left(\mathrm{Ea}_{\mathrm{E}}\right.$, and $\mathrm{Ea}_{\mathrm{tan} \delta}$, respectively), and their correlation coefficients $\left(\mathrm{R}^{2}\right)$. The activation energy values decrease with increasing content of HPC in the epoxy matrix, the trend is clear for $\mathrm{Ea}_{\mathrm{E}}$, but not for $\mathrm{Ea}_{\mathrm{tan} \delta}$ values whose decrease is not systematic. On the other hand, it is known that $\mathrm{T}_{\mathrm{g}}$ is related with the extent of the cure reaction ${ }^{[15]}$. Therefore the slight increase of $\mathrm{T}_{\alpha}$ with increasing HPC concentration, observed in Figure 5a (represented by circles), indicates that HPC is acting as an accelerator-catalyst. Concerning the correlation coefficients $\left(\mathrm{R}^{2}\right)$, the activation energies for the $\alpha_{\text {epoxy }}$ relaxation calculated from loss modulus (E") peaks are more reliable than those using the loss tangent $(\tan \delta)$ maxima. Whereas this $\alpha_{\text {epoxy }}$ relaxation was more quantitatively and accurately evaluated it is worth to compare its activation energy with reported values of activation energy of the glass transition. Samios and Riegel ${ }^{[23]}$ obtained for the same epoxy system in bulk, the activation energy of $630 \mathrm{~kJ} \cdot \mathrm{mol}^{-1}$ leading to the conclusion that in kinetic terms, or Ea terms, the epoxy system without HPC obtained by casting does not differ significantly $\left(624 \mathrm{~kJ} . \mathrm{mol}^{-1}\right)$ from that obtained in bulk. Moreover Li et al. ${ }^{[7]}$ also observed for a similar epoxy system that the activation energy values of the glass transition were around $500 \mathrm{~kJ} . \mathrm{mol}^{-1}$ while Goertzen et al. ${ }^{[9]}$ observed Ea values around $300 \mathrm{~kJ} \cdot \mathrm{mol}^{-1}$ for a carbon/DGEBA epoxy cured with an aliphatic amine. Considering the activation energy downward with

Table 1. Activation energies (Ea) and correlation coefficient $\left(\mathrm{R}^{2}\right)$ of the $\alpha_{\text {epoxy }}$ relaxation calculated from the shift of the $\tan \delta$ and E" peaks with frequency

\begin{tabular}{|c|c|c|c|c|}
\hline $\begin{array}{l}\text { wt. (\%) of } \\
\text { HPC }\end{array}$ & $\underset{\left(\mathbf{k J} . \mathbf{m o l}^{-1}\right)}{\mathbf{E a}{ }^{\prime-1}}$ & $\mathbf{R}^{2}$ & $\underset{\left(\mathbf{k J} . \mathbf{m o l}^{-1}\right)}{\mathbf{E a}_{\tan ^{-1}}}$ & $\mathbf{R}^{2}$ \\
\hline 0 & 624 & 0.9998 & 543 & 0.9663 \\
\hline 2 & 562 & 0.9987 & 429 & 0.8370 \\
\hline 4 & 543 & 0.9902 & 559 & 0.9902 \\
\hline 6 & 482 & 0.9996 & 484 & 0.9385 \\
\hline 8 & 513 & 0.9996 & 496 & 0.8930 \\
\hline 10 & 474 & 0.9996 & 425 & 0.9755 \\
\hline
\end{tabular}
for samples with different contents of HPC. the increasing of HPC content on $\alpha_{\text {epoxy }}$ relaxation and the presence of $\alpha_{\text {epoxy }}$ relaxation, two relevant aspects should be contributing to this singular behavior: the presence of the residual solvent quantities and the possible catalyst role of HPC. The hydroxyl groups of HPC and its semi-rigid polymer chain induce a microphase appearance during the curing process. The most significant differences seem to be in the values of $\alpha_{\text {epoxy }}$ and $\alpha_{\text {epoxy }}^{\prime}$ temperatures (as shown in Figures 4, 5a, b).

\section{Conclusions}

The dynamic mechanical relaxations of the epoxy system (DGEBA-DDM) crosslinked in the presence of the cellulose ether hydroxypropyl cellulose (HPC) were well identified by applying the DMTA technique for a long range of frequencies. It was observed that even low contents of HPC affect the behavior of the epoxy-amine network.

In HPC-epoxy systems obtained by casting, the presence of two $\alpha$ relaxations ( $\alpha_{\text {epoxy }}$ and $\alpha_{\text {epoxy }}$ ) was observed and distinguishes the glassy region from that typical of those systems cured in bulk where a single $\alpha$ relaxation is characteristic. Despite this, the activation energy value calculated for the $\alpha_{\text {epoxy }}$ relaxation (in $T_{\alpha}$ ) for neat epoxy system cured using casting does not differ significantly from that obtained at $\alpha$ relaxation (in $\mathrm{T}_{\mathrm{g}}$ ) in bulk.

The activation energy of the $\alpha_{\text {epoxy }}$ relaxation determined by loss modulus was more reliable than that based on tan delta. This was explained as a function of the fact that tan delta contains an elastic component. The addition of HPC lowered the activation energy of this $\alpha_{\text {epoxy }}$ relaxation because HPC possesses a semi-rigid polymer chain with hydroxyl groups performing interactions. Finally, it was observed the sui generis role of HPC that has acted in the epoxy matrix as a catalyst, a promoter of a second phase and a plasticizer.

\section{Acknowledgements}

CAPES-REUNI and CNPq for financial support and fellowships.

\section{References}

1. Martini, D. S.; Braga, B. A. \& Samios, D. - Polymer, 50, p.2919 (2009). http://dx.doi.org/10.1016/j.polymer.2009.03.058

2. Jin, F. L. \& Park, S. J. - J. Ind. Eng. Chem., 13, p.808 (2007).

3. Stefani, P. M.; Perez, C. J.; Alvarez, V. A. \& Vazquez, A. - J. Appl. Polym. Sci., 109, p.1009 (2008). http://dx.doi.org/10.1002/app.28162

4. Miranda, M. I. G.; Jacobs, C. A. B.; Bica, C. I. D. \& Samios, D. - J. Appl. Polym. Sci., 87, p.676 (2003). http://dx.doi.org/10.1002/ app. 11456

5. Ward, I. M. - "Mechanical Properties of Solid Polymers", 2nd ed., Wiley, New York (1990).

6. Haines, P. J. - "Thermal Methods of Analysis, Principles, Applications and Problems", Chapman and Hall, New York (1995).

7. Li, G.; Lee-Sullivan, P. \& Thring, R. W. - J. Therm. Anal. Calorim., 60, p.377 (2000). http://dx.doi.org/10.1023/A:1010120921582

8. Chen, D. Z.; Tang, C. Y.; Chan, K. C.; Tsui, C. P.; Yu, P. H. F.; Leung, M. C. P. \& Uskokovic, P. S. - Compos. Sci. Tech., 67, p.1617 (2007). http://dx.doi.org/10.1016/j.compscitech.2006.07.034

9. Goertzen, W. K. \& Kessler, M. R. - Compos. Part B, 38, p.1 (2007). http://dx.doi.org/10.1016/j.compositesb.2006.06.002

10. Karbhari, V. \& Wang, Q. - Compos. Part B-Eng., 35, p.299 (2004). http://dx.doi.org/10.1016/j.compositesb.2004.01.003

11. Peng, Z.; Kong, L. X. \& Li, S. D. - Synth. Metals, 152, p.25 (2005). http://dx.doi.org/10.1016/j.synthmet.2005.07.098 
12. Jung, N. \& Jeon, S. - Macromolecules, 41, p.9819 (2008). http://dx.doi. org/10.1021/ma8020695

13. Ghilarducci, A.; Salva, H. \& Marzocca, A. J. - J. Appl. Polym. Sci., 113, p.2361 (2009). http://dx.doi.org/10.1002/app.30332

14. Tang, Z.; Qi, L. \& Gao, G. - Solid State Ion., 179, p.1880 (2008). http:// dx.doi.org/10.1016/j.ssi.2008.05.011

15. Miranda, M. I. G. \& Samios, D. - Eur. Polym. J., 33, p.325 (1997).

16. Miranda, M. I. G.; Tomedi, C.; Bica C. I. D. \& Samios, D. - Polymer, 38, p.1017 (1997).

17. Ho, F. L.; Kohler, R. R. \& Ward, G. A. - Anal. Chem., 44, p.178 (1972). http://dx.doi.org/10.1021/ac60309a039

18. Murayama, T. - "Dynamic Mechanical Analysis of Polymer Materials", Elsevier, Amsterdam (1978).
19. Johari, G. P.; Mikolajczak, G. \& Cavaille, J. Y. - Polymer, 28, p.2023 (1987).

20. Mangion, M. B. M.; Wang, M. \& Johari, G. P. - J. Polym. Sci. Part B-Polym. Phys., 30, p.445 (1992).

21. Rials, T. \& Glasser, W. - J. Appl. Polym. Sci., 36, p.749 (1988). http:// dx.doi.org/10.1002/app.1988.070360402

22. Flynn, J. H. - J. Therm. Anal., 36, p.1579 (1990). http://dx.doi. org/10.1007/BF01914077

23. Riegel, I. C.; Freitas, L. L. \& Samios, D. - Polímeros, 3, p.58 (1999).

Enviado: 12/09/11

Reenviado: 09/03/12

Aceito: 23/04/12 